\title{
Effects of Posterior Association Cortex Lesions on Brain Potentials Preceding Self-Initiated Movements
}

\author{
Jaswinder Singh' and Robert T. Knight ${ }^{2}$ \\ 1Department of Psychology, Northwestern University, Evanston, Illinois 60208 and '2Department of Neurology, University of \\ California at Davis, Davis, California 94553
}

To assess the role of subregions of the posterior association cortex in movement control, we recorded movement-related potentials (MRPs) in patients who had lesions centered in the temporal-parietal junction (T-PCX; damaged areas 22, caudal 39, 40, and 42; $n=7$ ), superior parietal cortex (ParCx; damaged areas 5,7 , rostral 39 , and $40 ; n=5$ ), and posterior association cortex lesions involving both the temporal-parietal junction and the superior parietal structures (PosCx; damaged areas $7,22,39,40,41$, and $42 ; n=5$ ) and in 14 age-matched normal controls. MRPs were recorded in a selfpaced button-press task in which subjects performed a switch closure with the right, left, or both hands (experiment I, experiment II, and experiment III, respectively) under counterbalanced experimental conditions. Data epochs beginning $1400 \mathrm{msec}$ prior to and extending to $600 \mathrm{msec}$ after each motor response were recorded from scalp sites over the precentral, central, and parietal regions. Normal controls and patients with T-PCX lesions generated comparable vertex maximal, symmetrical readiness potentials (onset 1000 msec), contralaterally enhanced NS' values (onset 500 msec), and MP values (onset $100 \mathrm{msec}$ ) preceding voluntary selfpaced movements. Extensive lesions involving the posterior association cortex reduced MRP amplitudes. Patients with selective ParCx lesions also had marked reduction of MRPs under all experimental conditions. The MRP findings coupled with clinical and behavioral data on patients with parietalcortex lesions indicate that the superior parietal regions are part of a neural system necessary for movement preparation.

[Key words: movement-related potentials, readiness potential, temporal lobe, parietal lobe, volition, voluntary movements]

\footnotetext{
Received Jan. 6, 1992; revised Oct. 8, 1992; accepted Oct. 14, 1992.

This work was carried out at the Department of Neurology, University of Califomia at Davis, Veterans Administration Medical Center, Martinez. The work was supported by Javits Award NS21135 and the Veterans Administration Research Service. Support was also provided by NS30400 (M. Cooper, M.D.). We thank Clay Clayworth for technical assistance and David L. Woods for helpful suggestions in all phases of the project. We are thankful to Dubravka Cop for her secretarial help and Elisabeth $F$. Lanzl for manuscript preparation. The research was approved by the Institutional Review Boards of the Martinez Veterans Administration Medical Center and the University of California at Davis. All aspects of this research were carefully explained to both controls and patients, who gave written informed consent.

Correspondence should be addressed to Jaswinder Singh, FMI, MC1037, The University of Chicago, 5841 South Maryland Avenue, Chicago, IL 60637.

Copyright (C) 1993 Society for Neuroscience $0270-6474 / 93 / 131820-10 \$ 05.00 / 0$
}

Brain potentials associated with voluntary movements provide a direct measure of the neural activity preceding and following motion (Kornhuber and Deecke, 1964, 1965; Vaughan et al., 1968; Shibasaki et al., 1980; Libet et al., 1983). Movementrelated potentials (MRPs) have becn associated with psychological constructs such as readiness, preparation, initiation, planning, volition, and intention to act (Kornhuber and Deecke 1964, 1965; McAdam and Seal, 1969; Kutas and Donchin, 1980; Libet et al., 1982, 1983; Singh et al., 1990b). There is no agreement whether MRPs are specific to motor preparation or reflect a general cortical preparatory process.

Cortical recordings suggest that the primary sensorimotor cortex might be the major intracranial generator of MRPs. However, the brain regions that generate and modulate MRPs are still uncertain. A variety of evidence, including the results of MRP scalp topography (Vaughan et al., 1968; Singh et al., 1990b), animal recording (Arezzo and Vaughan, 1975; Johnson, 1980), cerebral blood flow (Roland et al., 1980), magnetoencephalographic (Deecke et al., 1983), and human lesion studies indicate that the voluntary motor preparatory process involves a neural circuit that includes motor, premotor, supplementary motor (SMA), as well as prefrontal and superior parietal cortices (Deecke et al., 1987; Knight et al., 1989; Singh and Knight, 1990). Subcortical structures including the thalamus (Sasaki et al., 1979, 1981), basal ganglia (Shibasaki, 1975), and hippocampal formation (Arezzo et al., 1987; Halgren, 1991) have also been implicated in MRP generation.

Clinical and behavioral studies have shown that patients with dorsolateral prefrontal and parietal cortex lesions show impairment of initiation, planning, or execution of simple or complex motor acts (ideomotor or ideational apraxia) (Fuster, 1980; Luria, 1980; Lynch, 1980; Hyvarinen, 1982; De Renzi et al., 1983; Andersen et al., 1985). Lesions in the SMA result in a sequencing abnormality in animals (Brinkman, 1981) as well as in humans (Dick et al., 1986). Patients with lesions of the basal ganglia and cerebellum also show difficulty in movement control and execution. A parietal lobe contribution to visuomotor control has been substantiated in the early (Dejerine and Mouzon, 1915; Kleist, 1934; Foerster, 1936) as well as in the more recent neurobehavioral literature (Pause et al., 1989). Thus, subregions of both anterior and posterior association cortices appear to contribute to voluntary movement execution. Further support for these notions is provided by neuroanatomic studies revealing bidirectional pathways between anterior and posterior association structures (Petrides and Pandya, 1984). The prefrontal 
cortex and parietal cortices also have direct input to premotor and motor regions (Jones et al., 1978; Barbas and Pandya, 1987; Pandya and Yeterian, 1989). These connections may form the cortical neural system that is engaged during voluntary motor preparation.

The presence of such a neural circuit would be supported by converging MRP data obtained from patients with discrete lesions of the anterior and posterior association cortex. During self-paced movements, lesions centered in the SMA have been shown to reduce the vertex maxima of the readiness potential (RP) (Deecke et al., 1987). MRP data obtained from patients with prefrontal lesions involving areas 6, 8, 9, and 46 show MRP reductions (Singh and Knight, 1990). Lesions in the human superior parietal cortex also reduce MRPs (Knight et al., 1989). MRPs have also bccn studicd in patients with subcortical pathology. Reduced MRPs have been reported in patients with idiopathic Parkinson's disease (Deecke and Kornhuber, 1978; Shibasaki et al., 1978; Dick et al., 1989; also see Barret et al., 1986; Singh et al., 1990a). However, normal MRPs have been recorded from patients with exposure to the neurotoxin 1-methyl4-phenyl-1,2,5,6-tetrahydropyridine (Singh et al., 1991), which produces focal cell loss in the substantia nigra (Davis et al., 1979; Langston and Ballard, 1984). Thus, the pars compacta region of the substantia nigra may not be critical for MRP generation. Loss of prefrontal or premotor dopamine input from the ventral tegmental region may be the cause of MRP reduction in Parkinson's disease. Patients with lesions in the dentate nucleus of the cerebellum also generate reduced MRPs (Shibasaki et al., 1986). Thus, the data on human lesions support contributions of the cerebellum and the frontostriatal structures in MRP generation.

MRP recordings in patients with focal brain damage can provide data on the neural regions generating and modulating scalp MRPs and information on the behavioral basis of MRP components. In earlier reports, we noted the contribution of the dorsolateral prefrontal and superior parietal cortex to MRP generation (Knight et al., 1989; Singh and Knight, 1990). However, the parietal MRP data were acquired in a speeded detection paradigm, making it difficult to compare the results to those of the conventional self-paced MRP studies. In the present study, we assessed MRPs in a self-paced button-press task in patients who had discrete unilateral lesions in the subregions of the human posterior association cortex.

\section{Materials and Methods}

\section{Lesion reconstruction}

Three groups of patients with infarcts in the distribution of the posterior branch of the middle cerebral artery (MCA) were studied. All lesions were at least 1 year post onset. Patients were initially selected based on unilateral lesions in the posterior association cortex evident on computerized tomography (CT) or magnetic resonance imaging. Lesions were transcribed onto corresponding CT templates by two independent raters (Knight et al., 1988). Software permitted reconstruction of the lateral perspective, determination of the lesion volume and cytoarchitectonic areas affected, and extraction of group-averaged lesions. Reconstruction details are presented elsewhere (Knight et al., 1988, 1989). Figures 1-3 show the average axial reconstructions and lateral views of the patients in the three groups. Group 1 (temporal-parietal) consisted of patients with infarcts in the angular branch of the MCA. Group 2 (parietal) consisted of patients with infarcts of the parietal branch of the MCA. Group 3 (posterior) consisted of patients with occlusion of the main trunk of the posterior division of the MCA involving the distribution of both the angular and parietal branches.

\section{Temporal-parietal group}

The temporal-parietal group (T-PCx) consisted of seven patients (all male; mean age $=61.08$ years, $S D=10.3$ ) with lesions centered in the temporal-parietal junction in Brodmann areas posterior 22 and 42, and caudal 39 and 40 (temporal-parietal; Fig. 1). Some subjects had extension into areas $7,5,3,1,2$, and 19 and areas 41 and 42 [four right (R), three left $(\mathrm{L})$; mean lesion volume $=34.9 \mathrm{cc}]$. In this group, $100 \%$ of the patients had lesions in areas 22 and 42 and caudal 39 and $40,64 \%$ in areas 7 and 19 , and $45 \%$ in area 5.

\section{Parietal group}

The parietal group ( $\mathrm{ParCx}$ ) consisted of five patients (four male; mean age $=62.2$ years, $\mathrm{SD}=8.9$ ) with lesions centered in the lateral parietal cortex in Brodmann's areas rostral 39 and 40 (supramarginal and angular gyri) and the inferior portion of areas 5 and 7 (parietal; Fig. 2). Some subjects had extension into areas $3,1,2$, and 19 and areas 41 and $42(1 \mathrm{R}, 4 \mathrm{~L}$; mean lesion volume $=31.98 \mathrm{cc})$. In this group, $100 \%$ of the patients had lesions in rostral areas 39 and $40,100 \%$ in areas 7 and 19 , and $40 \%$ in area 5 . Despite a substantial overlapping of lesions, T-PCx and ParCx groups were differentiated anatomically on the basis of involvement of areas 22 and 42 and caudal 39 and 40 in the T-PCx group versus rostral 39 and 40 in the ParCx group. None of the lesions from either group involved the hippocampus or other mesial limbic structures.

\section{Posterior association lesion group}

The posterior association cortex lesion ( $\mathrm{PosCx}$ ) group consisted of five patients (all male; mean age $=62.1$ years, $\mathrm{SD}=9.8$ ) with extensive lesions involving both the lateral parietal cortex and the temporal-parietal junction (posterior; Fig. 3; 2R, 3L; mean lesion volume $=95.0$ $\mathrm{cc})$. The posterior association lesion group had a larger lesion volume than did the other two groups (PosCx vs T-PCx, $t=4.47, p<0.003$; PosCx vs ParCx, $t=4.56, p<0.002$ ).

Clinical evaluation in these patients as recorded at the time of testing revealed moderate Wernicke's aphasia (three patients), mild finger agnosia (7 patients), conduction aphasia and stuttering (two patients), anomia (one patient), decreased proprioception and agraphesthesia (four patients), astereognosis and pseudoathetosis (two patients), mild hemianesthesia (three patients), and mild left-right difficulty (one patient). Neurologic examination showed neither marked hemiparesis nor pe. ripheral neuropathy. Patients with medical complications, psychiatric disturbances, substance abuse, or dementia were excluded. All patients were right-handed and were naive to the experiments. None of the patients showed any clinical signs or symptoms of anxiety or depression.

\section{Controls}

The control group consisted of 14 neurologically normal subjects (14 male; mean age $=59.3$ years, $S D-9.2)$ matched for age with the patient groups. They were members of the hospital staff personnel and the volunteer service of the hospital staff. Subjects with a history of substance abuse, psychiatric or medical disorders, dementia, or multiple neurologic events were excluded. All subjects gave informed consent and were paid for their participation. All subjects were right-handed.

\section{Experimental design and $M R P$ recordings}

MRP recording methods have been described in detail in prior reports (Singh and Knight, 1990a; Singh et al., 1990b, 1991). Briefly, MRPs were recorded with $\mathrm{Ag} / \mathrm{AgCl}$ electrodes placed at FP1 FPZ, FP2 (overlying the superior frontal gyrus), F3, FZ, F4 (mid-frontal gyrus, near superior frontal cortex), C3, CZ, C4 (precentral gyrus), and P3 and P4 (superior parietal lobule) (Homan et al., 1987). Three additional electrodes were placed over precentral areas denoted as $\mathrm{C} 3 \mathrm{a}, \mathrm{CZa}$, and $\mathrm{C} 4 \mathrm{a}$. These were located $2 \mathrm{~cm}$ anterior to $\mathrm{C} 3, \mathrm{CZ}$, and $\mathrm{C} 4$, respectively (between the precentral and superior frontal gyrus). All clectrodcs werc referenced to linked earlobes. A ground electrode was placed on the forehead. Electrooculogram (EOG) was recorded from an electrode below the right eye. EMG responses were recorded from a pair of electrodes placed on the thenar muscle and first metacarpal-phalangeal joint of the hand involved in the task. Electrode impedances were kept below $5 \mathrm{k} \Omega$. EEG, EOG, and EMG were recorded with Grass P511 amplifiers. EEG and EOG were amplified $(50 \mathrm{~K})$ and bandpass filtered from 0.01 to 100 


\section{TEMPORAL-PARIETAL ASSOCIATION CORTEX}

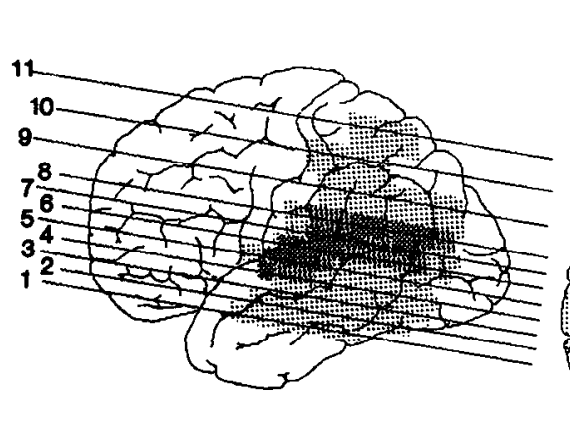

4
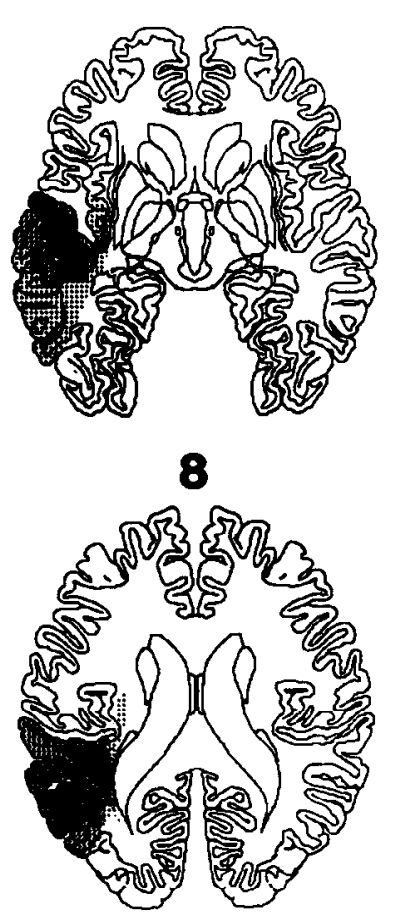

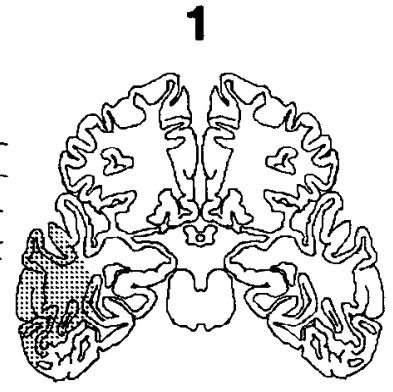

5

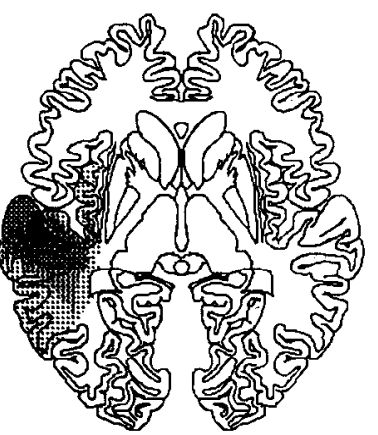

9

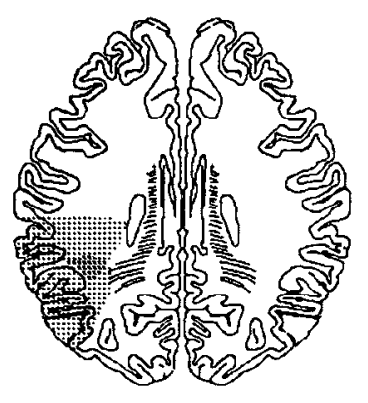

2



6

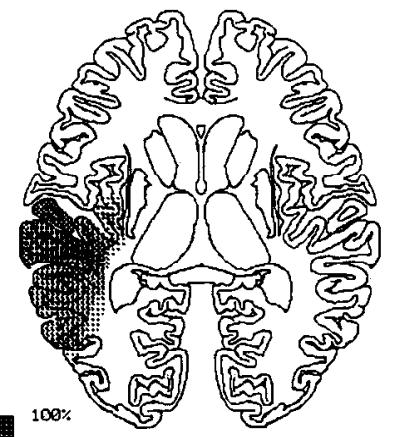

10

$80 \%$
$40 \%$
$20 \%$
$6 \%$

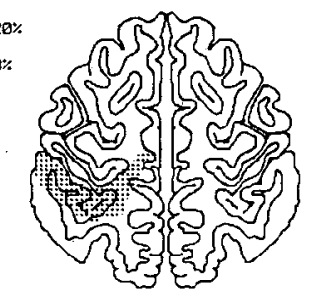

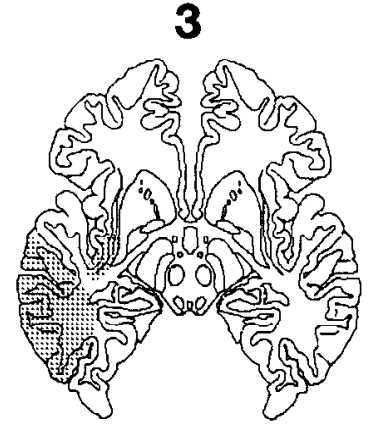

7

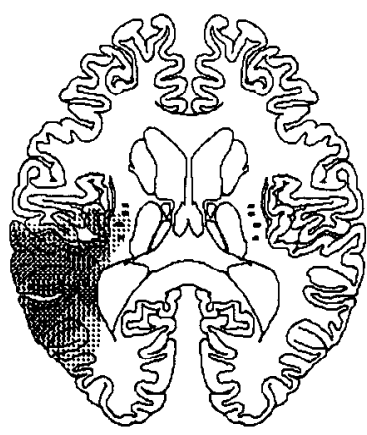

11

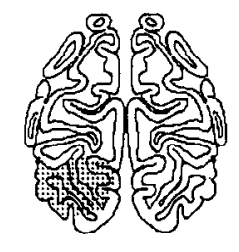

Figure 1. Lesion extent in patients with unilateral damage of temporal-parietal structures (T-PCx, $n=7,4 \mathrm{R}, 3 \mathrm{~L}$; mean lesion volume $=34.9$ cc). The lines on the lateral reconstruction indicate the location of the axial sections used in CT transcription. Lesions determined by CT scan from individual patients were transcribed onto $0^{\circ}$ to canthomeatal line templates. A lateral view of the lesion extent was then projected from the axial sections by software reconstruction methods. The digitized lesion data from individual subjects were then averaged to generate the group lesion densities for both lateral and axial views. Unilateral right-sided lesions have been reflected onto the left hemisphere. The scale indicates the percentages of patients with damage in the corresponding area; $100 \%$ implies that all patients had lesions in that area.

$\mathrm{Hz}$ (time constant $=5 \mathrm{sec}$ ). EMG activity was amplified $(10 \mathrm{~K})$ and filtered from 10 to $100 \mathrm{~Hz}$. Signals were digitized at a sampling rate of $128 \mathrm{~Hz} /$ channel by a PDP-1173 minicomputer. Digitized single trial epochs and coded button presses were stored on magnetic tape for offline averaging and analysis. The stored data were averaged from epochs of raw EEG beginning $1400 \mathrm{msec}$ prior to the trigger and continuing for $600 \mathrm{msec}$ post motion. Trials contaminated by eye blinks, excessive EMG activity, or amplifier blocking were rejected by the computer prior to averaging. Sums of $150-200$ artifact-free trials were obtained for each condition.

Procedure. The subject was seated in a comfortable reclining armchair in a dimly lit, electrically and acoustically shielded room. The subject was given a push button mounted on a bicycle handle grip. The subject was instructed to grasp the handle loosely in the palm and briskly press and release the button with the thumb. The button excursion was about $8 \mathrm{~mm}$. The button press was self-initiated and self-paced. To eliminate contributions from overlapping MRP epochs, subjects were trained in a practice session to produce responses with an intermovement interval (IMI) of 2-10 sec. Subjects were also instructed to avoid excess force in the button press. The participants were required to fix their gaze at the tip of the button under all conditions and were further instructed to avoid eye blinking or lateral eye movements during the button press. They were also tanght in the training session to delay the button press in case they blinked. The subjects understood that they were required to attempt to produce isolated thumb movements in the absence of other motor activity and were warned against synchronizing thumb movements with respiration.

The experiment was divided into three counterbalanced conditions. Conditions 1 and 2 consisted of unilateral thumb presses with either the right or left thumb (RHP, LHP). In condition 3, MRPs were recorded during simultaneous left and right thumb presses. Each experimental condition was separated by a $5 \mathrm{~min}$ rest period. Subject performance 


\section{PARIETAL ASSOCIATION CORTEX}

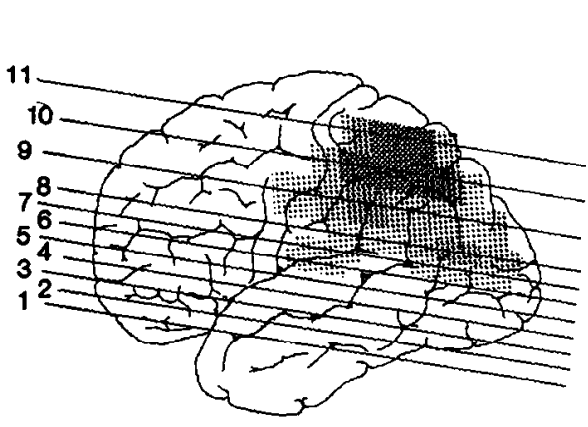

4

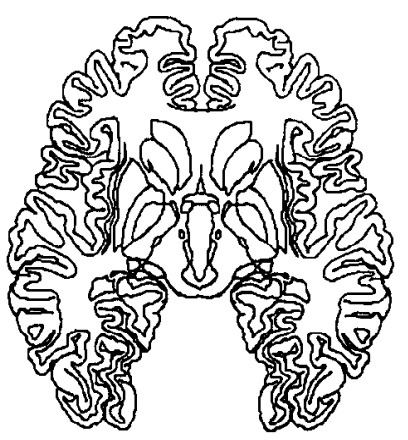

8

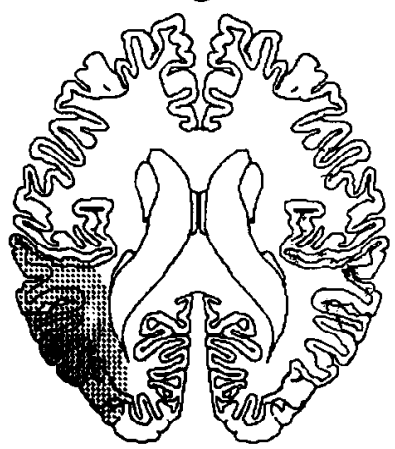

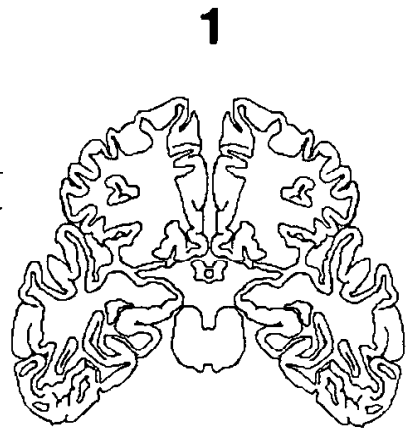

5

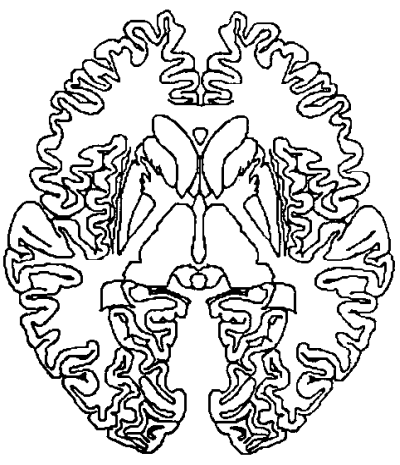

9



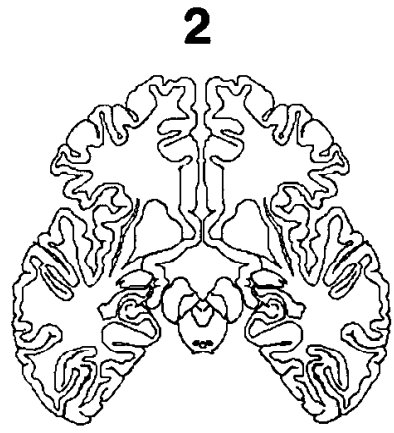

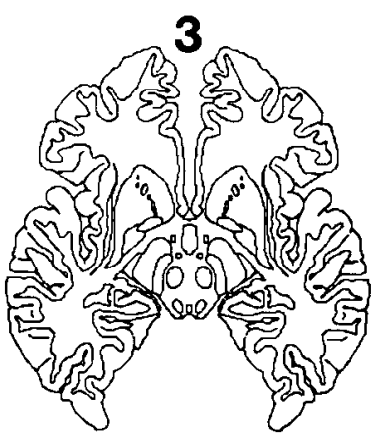

6



10

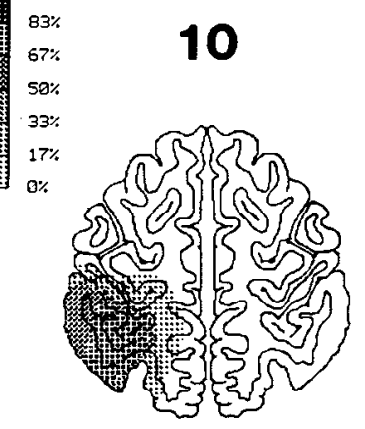

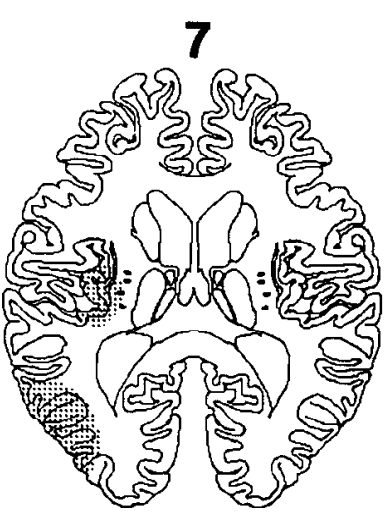

11

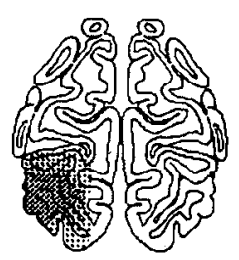

Figure 2. Lesion extent in patients with unilateral damage of parietal structures ( $\mathrm{ParCx} ; n=5,1 \mathrm{R}, 4 \mathrm{~L}$; mean lesion volume $=31.9 \mathrm{cc})$. See Figure 1 for other details.

was monitored on a closed circuit television monitor by the experimenter. The subject and the EEG were monitored for signs of drowsiness, and recording was halted if drowsiness was noted. Subjects were given feedback on their performance. Testing was completed in about $1.5 \mathrm{hr}$.

\section{Behavioral measures: IMI}

The subjects were required to perform self-paced switch closures in a 2-10 sec interpress interval. The IMI was quantified to assess whether there was any noticeable difference between patients and healthy controls, and also whether this variable could be correlated with the components of MRPs.
Data reduction and analyses

The method for identifying and measuring MRPs has been described in detail in prior reports (Singh and Knight, 1990a; Singh et al., 1990b) Briefly, three pre- and one postmotion component were identified based on individual and group mean averages. A regression line was fitted to these MRP phases. The first component, RP, was identified as the initial portion of the premovement negativity. This corresponds to the Bereitschaftspotential described by Deecke et al. (1969). The onset of this component was determined as a first negative deflection of 1.5 $\mu \mathrm{V}$ sustained for more than $20 \mathrm{msec}$. The second component, $\mathrm{NS}^{\prime}$, began at $450-500 \mathrm{msec}$ and peaked at about $100 \mathrm{msec}$ premotion. The $\mathrm{NS}^{\prime}$ represents the later portion of the RP. The third component, MP (or N2), refers to the additional negativity generated immediately (about 


\section{POSTERIOR ASSOCIATION CORTEX}


5
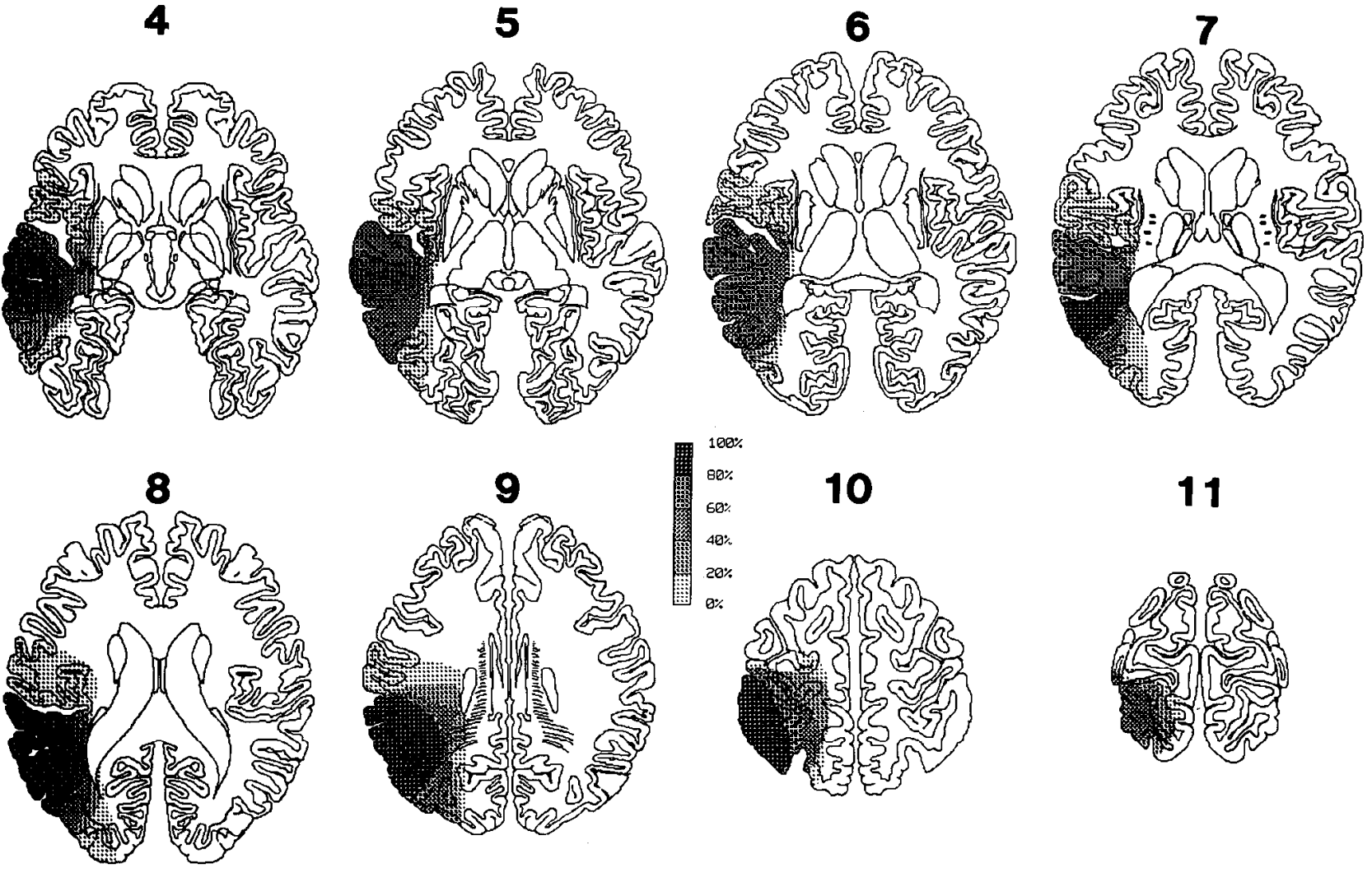

$100 \%$

10

60\%

$40 \%$

$20 \%$

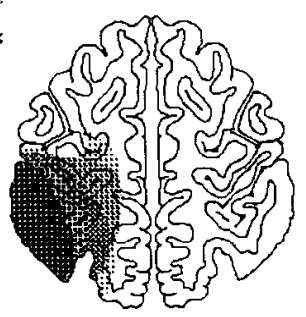

11

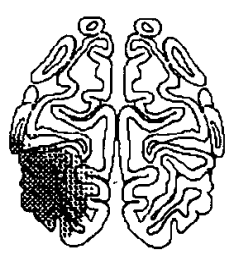

Figure 3. Lesion extent in patients with unilateral damage of posterior association cortex lesions $(\mathrm{PosCx} ; n=5,2 \mathrm{R}, 3 \mathrm{~L} ;$ mean lesion volume $=$ $95.0 \mathrm{cc}$ ). See Figure 1 for other details.

$100 \mathrm{msec}$ ) preceding the movement. The peak amplitude of the MP was measured at the trigger point. The MP is superimposed on the NS', and the NS' in turn is superimposed on the RP. In order to obtain pure measures of these components, we also used the subtraction method (Kutas and Donchin, 1974, 1980). The NS' was computed as the potential difference between the NS' and RP. The MP was also calculated as the potential difference between MP and the sum of RP and NS' components. The fourth component, postmotion positivity (P2), was measured 180-220 msec postmotion. Measurements were made on the individual records by means of a computer-assisted cursoring program. Mean MRP amplitudes were also calculated in restricted windows (i.e., RP: -1000 to $-500 \mathrm{msec}$; $\mathrm{NS}^{\prime}:-500$ to $-100 \mathrm{msec}$; MP: -100 to 0 msec).

Statistical analyses. The scalp-recorded voltages were subjected to repeated-measures univariate and multivariate (ANOVA, MANOVA) analysis of variance (subject $\times$ group $\times$ condition and electrode), with corrected $t$ tests for specific electrode comparisons. The initial statistical analysis was done with MANOVA, following which univariate analysis of variance was carried out. The relationship between behavioral measures and MRPs, and between lesion volume and MRPs, was examincd by correlation analysis.

\section{Results}

\section{Behavioral data}

$I M I$. All participants were able to carry out the task required for all three experimental conditions. No significant group differences were observed with regard to the IMI. Furthermore, 

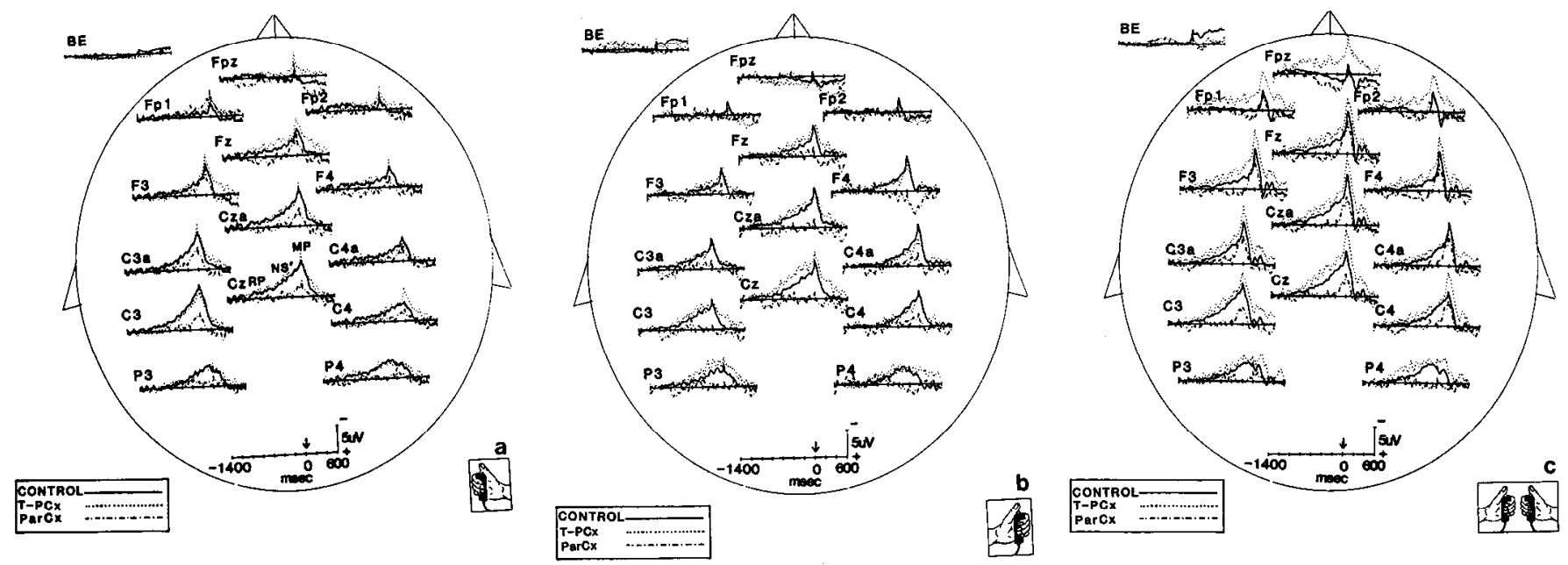

Figure 4. a, Overlapped group grand-averaged waveforms from controls (solid curves), patients with T-PCx (dotted curves), and ParCx lesions (dashed curves) in a self-paced right-hand button press. Note the contralateral enhancement of the MP in all three groups. 'The RP and NS' components are reduced over the central and precentral leads only in the ParCx-lesioned group relative to the T-PCx group. $b$, For the LHP condition also, the RP and NS' components are reduced over the central and precentral leads only in the ParCx-lesioned group. $c$, Note the absence of the contralateral enhancement in all three groups for the bimanual condition. The RP and NS' components of MRPs are reduced in the ParCxlesioned group. The late component MP is partially preserved. $B E$, below eye.
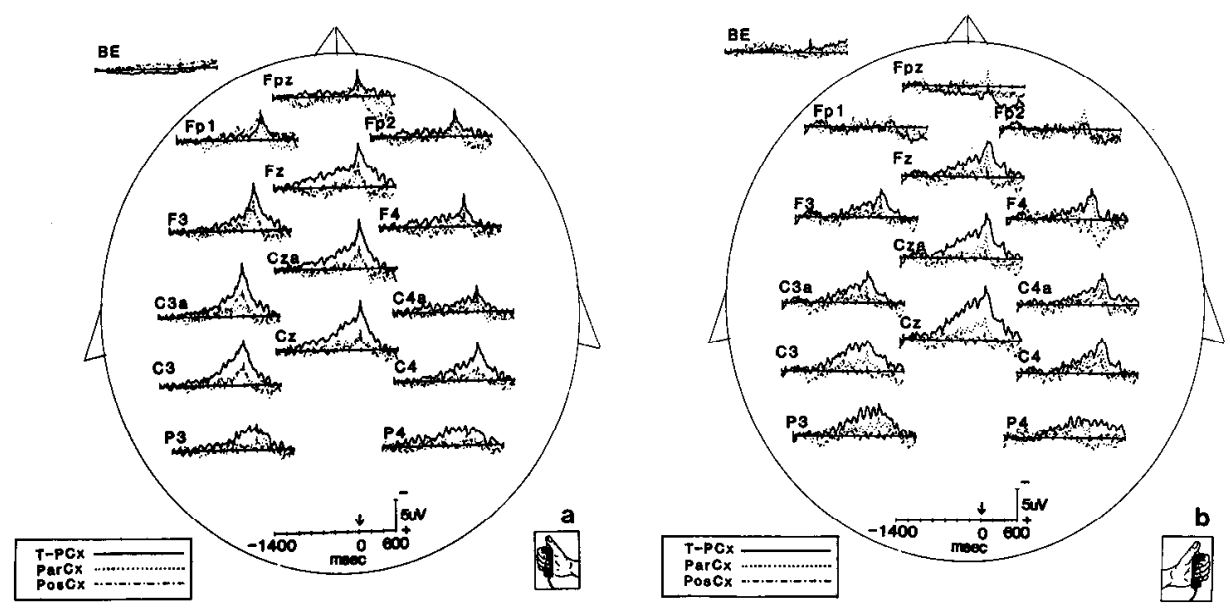

Figure 5. a, Overlapped group grandaveraged waveforms from patients with T-PCx (solid curves), ParCx (dotted curves), and PosCx lesions (dashed curves) in a self-paced right-hand button press. The RP and NS' components are reduced over the central and precentral leads in both the ParCx- and PosCx-lesioned groups relative to the T-PCx group. $b$, For the LHP condition also, the RP and 'NS' components are reduced over the central and precentral leads in both the ParCx- and PosCxlesioned groups. $B E$, below eye. clinical signs and symptoms in individual patients (i.e., aphasia) could not be correlated with MRP amplitudes.

$M R P$ data. MRPs recorded from controls and from T-PCx, ParCx, and PosCx groups are shown in Figures $4 a-c, 5 a, b$, and 6.

\section{Within-group analysis}

Control group. Controls generated a slowly developing negativity beginning at about $1000 \mathrm{msec}(\mathrm{CZ}$ : mean $=1012 \mathrm{msec})$ prior to the switch closure (RP). The RP was symmetric, bilaterally distributed, and maximal at frontocentral midline electrodes ( $\mathrm{CZ}$ and $\mathrm{CZa}$ ). The $\mathrm{NS}^{\prime}$ began at $500-450 \mathrm{msec}(480 \mathrm{msec}$ ) prior to the switch closure. The NS' was maximal over the frontocentral regions contralateral to movement [RHP: $\mathrm{C} 3$ vs $\mathrm{C} 4, t$ $(\mathrm{df}=25)=3.4, p<0.002$ ]. However, this effect was not significant in the LHP condition. The MP began at about $100 \mathrm{msec}$ prior to the switch closure. The MP was maximal over contralateral sites for both RHP and LHP [RHP: C3 vs C4, $t$ (df $=$ $20)=3.56, p<0.001]$. During the bimanual (BMP) condition, the MP component was enhanced relative to either of the unimanual conditions (RHP vs BMP: $p<0.05$ ). There was no significant contralateral MRP (NS' and MP components) enhancement during the bimanual switch closure condition. Therefore, no significant difference emerged between MRP amplitudes over ipsilateral and contralateral leads (e.g., for MP: $\mathrm{C} 3$ vs $\mathrm{C} 4, t=0.69, \mathrm{NS}$ ) during this condition.

Temporal-parietal group. The onset latency of the RP (CZ, $950 \mathrm{msec}$ ), NS' (431 msec), and MP (100 msec) components was comparable between the T-PCx and control groups. The T-Pcx scalp distribution was also similar to that of controls. The RP was distributed symmetrically and had its maximal amplitude at the vertex. Unimanual conditions produced an 


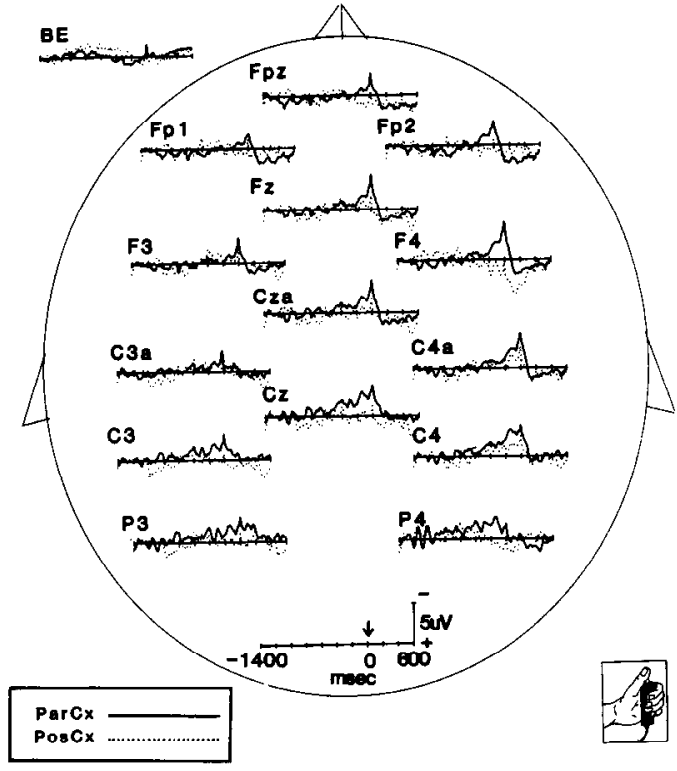

Figure 6. Overlapped group grand-averaged waveforms from patients with ParCx (solid) and PosCx lesions (dotted) in a self-paced left-hand button press task. $B E$, below eye.

asymmetric distribution of the NS' [RHP: C3 vs C4: $t(\mathrm{df}=11)$ $=3.3, p<0.01]$ and MP [RHP: C3 vs C4: $t(\mathrm{df}=11)=3.6, p$ $<0.01]$ components with maximum amplitude over the contralateral electrodes. During the BMP, all of the premovement components were distributed symmetrically over the scalp (e.g., for MP: C3 vs C4, $t=0.72, \mathrm{NS}$ ). The late component of the MRP (MP) was also significantly enhanced (RHP vs BMP: $p<$ 0.05).

Parietal group. The ParCx group generated a slowly developing negativity at about $500(488 \mathrm{msec})$ prior to the execution of the movement. The earliest portion of the MRPs, the RP, was either absent or markedly reduced. Two of five patients produced a barely discernible RP. The NS' was produced at least by four of the five patients, and the MP component was observable in all five patients. Unlike the results for the controls and T-PCx group, amplitudes of the NS' [RHP: C3 vs C4: $t$ (df $=8)=0.73, \mathrm{NS}$ ] and MP [RHP: C3 vs C4: $t(\mathrm{df}=8)=1.2$, NS] components were not significantly enhanced over contralateral electrodes in unimanual conditions. The MP component was not significantly enhanced during the BMP condition (RHP vs BMP: $p>0.05$ ).

Posterior association group. All three MRP components were either absent or markedly reduced in this group. Although considerably reduced, the MP component was identifiable in all five patients. The scalp topographic distribution did not change with the task. For example, the MP component was nonsignificantly [RHP: C3 vs C4: $t(\mathrm{df}=8)=0.48, \mathrm{NS}$ ] lateralized to the contralateral hemisphere.

\section{Between-group analysis}

$R P$. The overall ANOVA between groups was significant $[F=$ $(\mathrm{df}=3,27)=4.9, p<0.01]$. Specific comparisons revealed that patients with PosCx and ParCx lesions had significant RP reduction relative to controls and to patients with $\mathrm{T}-\mathrm{PCx}$ lesions (see Table 1). There was no significant difference between control and T-PCx groups under any experimental condition.

\begin{tabular}{lcl}
\hline $\begin{array}{l}\text { Table 1. Mean between-group comparisons of the amplitude (in } \boldsymbol{\mu V} \text { ) } \\
\text { for the RP, NS', and MP components of MRPs }\end{array}$ & \multicolumn{1}{l}{$p$ values } \\
Groups & \multicolumn{1}{l}{} \\
\hline RP & 18.2 & 0.001 \\
Control versus ParCx & 1.3 & NS \\
Control versus T-PCx & 8.3 & 0.01 \\
Control versus PosCx & 3.7 & 0.01 \\
T-PCx versus PosCx & 4.9 & 0.01 \\
T-PCx versus ParCx & 5.8 & 0.03 \\
PosCx versus ParCx & & \\
NS' & 33.7 & 0.001 \\
Control versus ParCx & 1.9 & NS \\
Control versus T-PCx & 19.1 & 0.001 \\
Control versus PosCx & 4.1 & 0.01 \\
T-PCx versus PosCx & 4.8 & 0.01 \\
T-PCx versus ParCx & 7.4 & 0.01 \\
PosCx versus ParCx & & \\
MP & 61.3 & 0.001 \\
Control versus ParCx & 1.6 & NS \\
Control versus T-PCx & 17.6 & 0.001 \\
Control versus PosCx & 6.7 & 0.001 \\
T-PCx versus PosCx & 5.4 & 0.01 \\
T-PCx versus ParCx & 6.5 & 0.01 \\
PosCx versus ParCx & & \\
\hline
\end{tabular}

$N S^{\prime}$. The overall ANOVA again showed significant group effects $[F=(\mathrm{df}=3,27)=4.55, p<0.01]$. Although partially preserved, the $\mathrm{NS}^{\prime}$ component was significantly reduced in PosCx- and ParCx-lesioned groups when compared with the control as well as T-PCx groups (Table 1). The subtraction method employed for obtaining pure $\mathrm{NS}^{\prime}$ yielded similar results.

$M P$. Although observable in the scalp recordings, the MP was significantly reduced both in the $\mathrm{ParCx}$ and $\mathrm{Pos} \mathrm{Cx}$ groups $[F$ $(\mathrm{df}=3,27)=4.38, p<0.01]$ (see Table 1). The subtraction method employed for extracting a pure MP uncontaminated by the RP and NS' yielded no significant difference between control and ParCx groups, supporting a partial preservation of this component in the ParCx group.

Analyses of the mean trials obtained from control and experimental groups after artifact rejection for all experimental conditions (c.g., percentagc of artifact rcjcction for RHP: T-PCx $=22 \%, \operatorname{ParCx}=24 \%, \operatorname{PosCx}=26 \%$, control $=23 \%$ ) were not significantly different across groups.

\section{Discussion}

Consistent with prior reports (Kutas and Donchin, 1980; Singh and Knight, 1990a; Singh et al., 1990a), different scalp topographies were observed in unimanual and bimanual conditions. Unimanual conditions with RHP and LHP produced symmetrical RPs, and asymmetrical NS' values and MP values with maximal amplitude contralateral to the movement. The bimanual condition differentially enhanced the MP component.

Patients with T-PCx lesions had MRPs comparable to that of controls in all experimental conditions. However, unilateral posterior lesions encompassing the superior parietal cortex reduced or abolished MRP components and delayed the onset of premovement negativity. The present results do not seem to be 
due to a general lesion effect or to slowness or difference in the force of pressing the button, because patients with T-PCx lesions comparable in size to the ParCx lesions had intact MRPs. Possible differences in force applied to the button press do not explain the results because force differentially affects the MP component (Kristeva et al., 1990), which was the component most preserved in $\mathrm{ParCx}$ - and PosCx-lesioned groups.

These results support the role of the lateral parietal cortex, including rostral portions of areas 39 and 40 (angular and supramarginal gyri) and area 7, in MRP generation. These findings are consistent with a previous study showing impaired MRPs in a speeded reaction time task in patients with parietal lesions. Both studies indicate that the parietal lobe provides input to the sensorimotor cortex several hundred milliseconds prior to the execution of a motor task (Knight et al., 1989).

Similar to prior findings (Knight et al., 1989), unilateral lesions showed a bilateral reduction of MRPs without unilateral reduction over the lesioned hemisphere. The finding of a bilateral MRP defect after unilateral lesions is compatible with clinical reports showing that unilateral parietal lesions in humans can result in apraxia in both limbs. Each parietal lobe appears to exert a bilateral hemispheric influence. Intracallosal connections may provide the pathways necessary for the unilateral parietal cortex to influence sensorimotor cortices bilaterally, either by direct connections or through relays in the prefrontal, premotor, or supplementary cortex (Jones and Powell, 1969; Jones et al., 1978).

Existing data from MRP scalp topography and from magnetic and blood flow studies support MRP sources in the precentral structures, including premotor, motor, and supplementary motor areas. Intracranial and subdural recordings in human subjects indicate that a major contribution to the scalp MRP may arise in the hand sensorimotor cortex (Lee et al., 1986; Neshige et al., 1988a,b). The results of animal studies are inconsistent on this issue. Some investigators have reported that the N1 (RP) and N2 (MP) arise in the pre- and postcentral structures and have a common neural source (Arezzo et al., 1977). These workers stressed that the human MP had its origin exclusively in the hand area of the precentral motor cortex.

In contrast to these findings, Pieper et al. (1980) compared the responses of the monkey and humans, and they reported the earliest onset of negativity at the motor hand area, followed by activity in the premotor area (areas 6 and 4 ). Neurons in the primary sensory cortex discharge $60-80 \mathrm{msec}$ later than do neurons in the precentral cortex (Evarts, 1972). Slow potential changes in the contralateral forelimb motor area 4 and premotor area 6 preceding hand movement by nearly $1 \mathrm{sec}$ have been recorded in monkeys (Hashimoto et al., 1979). Other investigators have reported firing of neurons in the premotor area 6 at about -100 to $-300 \mathrm{msec}$ prior to movement (Kubota et al., 1974). In support of the SMA contribution to human MRPs (Deecke et al., 1987), Brinkman and Porter (1979), in a selfpaced task in monkeys, demonstrated SMA unit activity about $250 \mathrm{msec}$ before the molor cortex cells fire. Johnson (1980) found the earliest onset of slow negativity at areas 9,10 , and 46 of the prefrontal cortex about $2 \mathrm{sec}$ prior to movement when there was no activity in motor areas.

Gemba et al. (1987) failed to record RPs from various loci of the prefrontal cortex in the monkey. However, Fuster (1980) reported that neurons in the prefrontal cortex fire several hundred milliseconds prior to the execution of a motor task in a typical delayed-response or delayed-alternation task. Premotor and motor neurons fire immediately preceding a motor response. Lesion data obtained from human subjects involving prefrontal area 9, 46, 6, and 8 lesions showing MRP reductions are consistent with these findings (Singh and Knight, 1990). The MRP reductions are most severe for lesions in areas 6 and 8 . Unilateral lesions of the SMA show a significant RP reduction at the vertex (Deecke et al., 1987), although recent magnetic data do not support the SMA hypotheses of MRP generation (Cheyne and Weinberg, 1989). Despite discrepancies in the primate literature, precentral structures including the premotor, supplementary motor, and prefrontal cortex appear to contribute to MRP generation or modulation.

The MRP reductions in the ParCx group are remarkably similar to the previously reported results for patients with prefrontal lesions. This suggests that the prefrontal areas 6 and 8 and the posterior association cortex involving areas 7 and rostral 39 and 40 may be necessary for MRP generation. These areas likely provide critical modulatory input into MRP generation in the sensorimotor cortex. These results are consistent with neurobehavioral data (Freund, 1986; De Renzi and Luchelli, 1988; Pause and Freund, 1989; Pause et al., 1989) indicating a significant contribution of premotor and superior parietal regions to planning, initiation, and visuomotor control.

All patients were able to perform the experimental task adequately but only patients with superior parietal involvement had MRP reductions. This raises the issue of what is the underlying behavioral significance of premovement potentials. For reasons discussed previously it is unlikely that the MRP reductions are due to simple changes in the force or rate of the switch closure. A more plausible explanation is that the critical behavioral factors associated with MRP generation were not monitored with enough sensitivity in the current experiments. For instance, a premotor-superior parietal network has been suggested to be critical for visuomotor control. Abnormalities in this control system would not be readily observable in the simple one-vector thumb movement employed in the current studies but might be quantifiable in a three-dimensional movement task.

\section{References}

Andersen RA, Essick GK, Seigal RM (1985) The encoding of spatial location by posterior parietal neurones. Science 230:456-458.

Arezzo J, Vaughan HG Jr (1975) Cortical potentials associated with voluntary movements in monkey. Brain Res 88:99-104.

Arezzo J, Vaughan HG Jr, Koss B (1977) Relationship of neuronal activity to gross movement related potentials in monkcy pre- and postcentral cortex. Brain Res 132:362-369.

Arezzo J, Tenke CT, Vaughan HG Jr (1987) Movement-related potentials within the hippocampal formation of the monkey. Brain Res 401:79-86.

Barbas H, Pandya DN (1987) Architecture and frontal cortical connections of the premotor cortex (area 6) in the rhesus monkey. J Comp Neurol 256:21 1-228.

Barret G, Shibasaki H, Neshige R (1986) Cortical potential shifts preceding voluntary movement are normal in parkinsonism. Electroencephalogr Clin Neurophysiol 63:340-348.

Brinkman C (1981) Lesions in supplementary motor area interfere with a monkey's performance of a bimanual coordination task. Neurosci Lett 27:267-270.

Brinkman C, Porter R (1979) Supplementary motor area in the monkey: activity of the neurons during performance of a learnt motor test. J Neurophysiol 12:681-709.

Cheyne D, Weinberg H (1989) Neuromagnetic fields accompanying 
unilateral finger movements: pre-movement and movement-evoked fields. Exp Brain Res 78.

Davis GC, Williams AC, Markey SP, Ebert MH, Caine ED, Reicher CM, Kopin IJ (1979) Chronic parkinsonism secondary to intravenous injection of meperidine analogues. Psychiatry Res 1:249-254.

Deecke L, Kornhuber HH (1978) An electrical sign of participation of the mesial 'supplementary motor cortex' in human voluntary finger movement. Brain Res 159:473-476.

Deecke L, Scheid P, Kornhuber HH (1969) Distribution of readiness potential, premotion positivity, motor potential of the human cerebral cortex preceding voluntary finger movement. Exp Brain Res 7:158168.

Deecke L, Boschert J, Weinberg H, Brickett P (1983) Magnetic fields of the human brain (Bereitschaftsmagnetfeld) preceding voluntary foot and toe movements. Exp Brain Res 52:81-86.

Deecke L, Lang W, Heller HJ, Hufnagl M, Kornhuber HH (1987) Bereitschaftspotential in patients with unilateral lesions of the supplementary motor area. J Neurol Neurosurg Psychiatry 50:1430-1434.

Dejerine J, Mouzon J (1915) Deux cas de syndrome sensitif cortical. Rev Neurol 28:388-392.

De Renzi E, Lucchelli F (1988) Ideational apraxia. Brain 111:11731185 .

De Renzi E, Lucchelli F, Faglioni P, Vecchi A (1983) Performance of left brain-damaged patients on imitation of single and motor sequences: frontal and parietal patients compared. Cortex 19:333-343.

Dick JPR, Benecke R, Rothwell JC, Day BL, Marsden CD (1986) Simple and complex movements in a patient with infarction of the right supplementary motor area. Movement Dis 1:255-266.

Dick JPR, Rothwell JC, Day BL, Cantello R, Buruma O, Gious M, Benecke R, Berardelli A, Thompson PD, Marsden CD (1989) The Bereitschaftspotential is abnormal in Parkinson's disease. Brain 112: 233-244.

Evarts EV (1972) Contrast between activity of precentral and postcentral neurons of cerebral cortex during movement in the monkey. Brain Res 40:25-31.

Foerster O (1936) Motorische Felder und Bahnen. In: Handbuch der Neurologie (Bumke H, Foerster O, eds), pp 1-357. Berlin.

Freund HJ (1986) Abnormalities of molor behavior after cortical lesions in humans. In: Handbook of physiology (Mountcastle VB, ed), pp 763-810. Bethesda, MD: American Physiological Society.

Fuster JM (1980) The prefrontal cortex. New York: Raven.

Gemba H, Tsujimoto T, Sasaki K (1987) Contingent negative variation (CNV) and readiness potential (RP) in the frontal lobe of monkeys. J Physiol Soc Jpn 429.

Gilden L, Vaughan HG, Costa LD (1966) Summated human EEG potentials with voluntary movement. Electroencephalogr Clin Neurophysiol 20:433-438.

Halgren E (1991) Firing of hippocampal units in relation to voluntary movement. Hippocampus 1:153-161.

Hashimoto S, Gemba H, Sasaki K (1979) Analysis of slow cortical potentials preceding self-paced hand movements in monkey. Exp Neurol 65:218-229.

Homan RW, Herman JH, Deecke L, Purdy P (1987) Cerebral location of 10-20 system electrode placement. Electroencephalogr Clin Neurophysiol 66:376-382.

Hyvarinen J (1982) Posterior parietal lobe of the primate brain. Physiol Rev 62:1060-1129.

Johnson JR (1980) Event-related potentials accompanying voluntary movements in rhesus monkey. In: Progress in brain research, Vol 54 (Kornhuber HH, Deecke I, eds). Amsterdam: Elsevier.

Jones EG, Powell TPS (1969) Connexions of the somatic sensory cortex of the rhesus monkey. II. Ipsilateral cortical connexions. Brain 92:717-730.

Jones EG, Coulter JD, Hendry SHC (1978) Intracortical connectivity of architectonic fields in the somatic, sensory, motor and parietal cortex of monkeys. J Comp Neurol 181:291-348.

Kleist K (1934) Gehirnpathologie. Leipzig: Barth.

Knight RT, Scabini D, Woods DL, Clayworth C (1988) The effects of lesions of superior temporal gyrus and inferior parietal lobe on temporal and vertex components of the AEP. Electroencephalogr Clin Neurophysiol 70:499-509.

Knight RT, Singh J, Woods DL (1989) Premovement parietal lobe input to sensorimotor cortex. Brain Res 498:190-194.

Kornhuber HH, Deecke L (1964) Hirnpotentialänderungen beim
Menschen vor und nach Willkürbewegungen, dargestellt mit Magnetband-Speicherung und Rückwärtsanalyse. Pfluegers Arch 281:52.

Kornhuber HH, Deecke L (1965) Hirnpotentialänderungen, bei Willkürbewegungen und passiven Bewegungen des Menschen: Bereitschafspotential und Reafferente Potentiale. Pfluegers Arch 284:1-17.

Kristeva R, Cheyne W, Lang W, Lindinger G, Deecke L (1990) Movement-related potentials accompanying unilateral and bilateral finger movements with different inertial loads. Electroencephalogr Clin Neurophysiol 75:410-418.

Kubota K, Iwammoto T, Suzuki H (1974) Visuokinetic aclivities of primate prefrontal neurons during delayed response performance. $\mathrm{J}$ Neurophysiol 197-212.

Kutas M, Donchin E (1974) Studies of squeezing: handedness, responding hand, response force, and asymmetry of readiness potential. Science 186:545-548.

Kutas M, Donchin E (1980) Preparation to respond as manifested by movement related brain potentials. Brain Res 202:95-115.

Langston JW, Ballard PA (1984) Parkinsonism induced by 1-methyl4-phenyl-1,2,3,6-tetrahydropyridine (MPTP): implications for treatment and the pathogenesis of Parkinson's disease. Can J Neurol Sci 11:160-165.

Lee BI, Luders H, Lesser RP, Dinner DS, Morris HH (1986) Cortical potentials related to voluntary and passive finger movements recorded from subdural electrodes in humans. Ann Neurol 20:32-37.

Libet B, Wright EW Jr, Gleason CA (1982) Readiness potential preceding unrestricted spontaneous vs preplanned voluntary acts. Electroencephalogr Clin Neurophysiol 3:322-335.

Libet B, Gleason CA, Wright EW Jr, Pearl DK (1983) Time of conscious intention to act in relation to onset of cerebral activities (readiness potential): the unconscious initiation of a freely voluntary act. Brain 106:623-642.

Luria (1980) Higher cortical functions in man. New York: Basic Books.

Lynch JC (1980) The functional organization of posterior parietal association cortex. Behav Brain Sci 3:485-534.

McAdam DW, Seal DM (1969) Bereitschafts potential cnhanccment with increased level of motivation. Electroencephalogr Clin Neurophysiol 27:73-75.

Neshige R, Luders H, Friedman L, Shibasaki H (1988a) Recording of movement-related potentials from scalp and cortex of man. Brain 111:719-736.

Neshige R, Luders H, Friedman L, Shibasaki H (1988b) Recording of movement-related potentials from the human cortex. Ann Neurol $24: 439-445$

Pandya DN, Yeterian EH (1989) Architecture and connections of cortical association areas, pp 3-62. New York: Plenum.

Pause M, Freund $H$ (1989) Role of the parietal cortex for sensorimotor transformation. Evidence from clinical observations. Brain Behav Evol 33:136-140.

Pause M, Kunesch E, Binkofski F (1989) Sensori-motor disturbanccs in patients with lesions of the parietal cortex. Brain 112:1599-1625.

Petrides M, Pandya DN (1984) Projections to the frontal cortex from the posterior parietal region in the rhesus monkey. J Comp Neurol 228:105-116.

Pieper CF, Goldring S, Jenny AB, MacMahon JP (1980) Comparative study of cerebral cortical potentials associated with voluntary movements in monkey and man. Electroencephalogr Clin Neurophysiol 48:266-292.

Roland PE, Larsen B, Lassen NA, Skinhoj E (1980) Supplementary motor area and other cortical areas in organization of voluntary movements in man. J Neurophysiol 43:118-136.

Sasaki K, Gemba H, Hashimoto S, Mizuno S (1979) Influences of cerebellar hemispherectomy on slow potentials in the motor cortex preceding self paced movements in the monkey. Ncurosci Lett 15: 23-28.

Sasaki K, Gemba H, Hashimoto S (1981) Pre-movement slow cortical potentials in self paced hand movements and thalamo-cortical and cortico-cortical responses in the monkey. Exp Neurol 72:41-50.

Shibasaki H (1975) Movement associated cortical potentials in unilateral cerebral lesions. J Neurol 209:189-198.

Shibaski H, Shima F, Kuroiwa Y (1978) Clinical studies of the movement related cortical potentials (MP) and the relationship between the dentatorubrothalamic pathway and readiness potential (RP). J Neurol 219:15-25.

Shibasaki H, Barret G, Halliday E, Halliday AM (1980) Components 
of the movement-related cortical potentials and their scalp topography. Electroencephalogr Clin Neurophysiol 49:213-226.

Shibasaki H, Barret G, Neshige R, Hirata I, Tomoda H (1986) Volitional movement is not preceded by cortical slow negativity in cerebellar dentate lesion in man. Brain Res 368:361-365.

Singh J, Knight RT (1990) Frontal lobe contribution to voluntary movements in humans. Brain Res 531:45-54.

Singh J, Bloem BR, Knight RT, Jagust W, Woods DL, Beckley DJ, Tetrud T, Langston JW (1990a) Movement-related potentials in patients with 1-methyl-4-phenyl-1,2,3,6-tetrahydropyridine-induced parkinsonism and early- and late-onset Parkinson's disease. Ann Neurol 28:235-236.

Singh J, Knight RT, Woods DL, Beckley DJ, Clayworth C (1990b) Lack of age effects on human brain potentials preceding voluntary movements. Neurosci Lett 119:27-31.

Singh J, Knight RT, Rosenlicht N, Kotun JM, Beckley DJ, Woods DL (1991) Abnormal premovement brain potentials in schizophrenia. Schizophr Res 8:31-41.

Vaughan HG, Costa LD, Ritter W (1968) Topography of the human motor potential. Electroencephalogr Clin Neurophysiol 25:1-10. 